\title{
Inclusão digital e literacia em saúde: uma experiência educativa em tempos de
}

\section{pandemia do Covid-19}

\author{
Digital inclusion and health literacy: the education experience in times of Covid-19 Pandemic \\ Inclusión digital y alfabetización en salud: una experiencia educativa en tiempos de la pandemia
}

Covid-19

Recebido: 01/02/2022 | Revisado: 06/02/2022 | Aceito: 09/02/2022 | Publicado: 14/02/2022

\author{
Joaquim Teixeira Netto \\ ORCID: https://orcid.org/0000-0002-7392-9166 \\ Fundação Oswaldo Cruz, Brasil \\ E-mail: joaquimtnetto@gmail.com \\ Zelia Pimentel Andrade \\ ORCID: https://orcid.org/0000-0002-2248-3010 \\ Fundação Oswaldo Cruz, Brasil \\ E-mail: zeliaandradere@gmail.com \\ Mario Roberto Vieira Rabelo Romano \\ ORCID: https://orcid.org/0000-0002-5393-3985 \\ Fundação Oswaldo Cruz, Brasil \\ E-mail: mario.romano@ensp.fiocruz.br
}

\begin{abstract}
Resumo
As rápidas transformações sociais desencadeadas pelas Tecnologias da Informação e Comunicação (TICs) e pela pandemia de Covid-19 trouxeram um desafio no campo da educação e saúde. O questionamento se o acesso as TICs estão ampliando (favorecendo) as desigualdades socias tornou-se mais premente do que nunca diante da pandemia Covid-19. Como diminuir a exclusão digital e a desinformação em saúde é o questionamento que este artigo busca responder. Assim, descrevemos uma experiência educativa em alfabetização digital e literacia em saúde durante a pandemia do Covid-19 por meio de estratégias remotas de ensino-aprendizagem usando recursos audiovisuais e oficinas dialógicas com moradores de baixa renda de um grande centro urbano no Brasil. A metodologia utilizada na pesquisa é qualitativa com a avaliação de alunos e professores. Como resultado das oficinas, foi possível observar resultados positivos que possibilitaram a divulgação de conhecimentos para a inclusão digital, social, além da promoção da saúde e o empoderamento do cidadão.
\end{abstract}

Palavras-chave: Educação digital; Comunicação digital; Inclusão social; Literacia em saúde; Covid-19.

\begin{abstract}
The fast social transformations triggered by Information and Communication Technologies (ICTs) and by the Covid19 pandemic brought a challenge in the field of education and health. The question whether access to ICTs is increasing (favoring) social inequalities has become more pressing than ever in the face of the Covid-19 pandemic. How to reduce the digital divide and misinformation in health is the question that this article seeks to answer. Thus, we describe an educational experience in digital literacy and health literacy during the Covid-19 pandemic through remote teaching-learning strategies using audiovisual resources and dialogic workshops with low-income residents of a large urban center in Brazil. The methodology used in the research is qualitative with the use of assessment for students and teachers. As a result of the workshops, it was possible to observe positive results that enabled the dissemination of knowledge for digital and social inclusion, in addition to health promotion and citizen empowerment. Keywords: Digital education; Digital communication; Social inclusion; Health literacy; Covid-19.
\end{abstract}

\section{Resumen}

Las rápidas transformaciones sociales provocadas por las Tecnologías de la Información y la Comunicación (TIC) y por la pandemia Covid-19 trajeron un desafío en el campo de la educación y la salud. La cuestión de si el acceso a las TIC está aumentando (favoreciendo) las desigualdades sociales se ha vuelto más urgente que nunca ante la pandemia de Covid-19. Cómo reducir la brecha digital y la desinformación en salud es la pregunta que este artículo busca dar respuesta. Así, describimos una experiencia educativa en alfabetización digital y alfabetización en salud durante la pandemia Covid-19 a través de estrategias de enseñanza-aprendizaje a distancia utilizando recursos audiovisuales y talleres dialógicos con residentes de bajos ingresos de un gran centro urbano de Brasil. La metodología utilizada en la investigación es cualitativa con el evaluación para estudiantes y profesores. Como resultado de los talleres se pudo observar resultados positivos que posibilitaron la difusión de conocimientos para la inclusión digital y social, además de la promoción de la salud y el empoderamiento ciudadano.

Palabras clave: Educación digital; Comunicación digital; Inclusión social; Alfabetización en salud; Covid-19. 


\section{Introdução}

A utilização da internet e das TICs tem sido cada vez maior em nossa sociedade. As TICs oferecem oportunidades inéditas tanto para o acesso, quanto para a produção e divulgação de informações. Estamos vivendo uma realidade em que toda a economia está centrada na internet (Neto et al., 2019).

Vivemos na sociedade da informação, na qual economias e culturas se interligam por meio das tecnologias de informação e comunicação, resultando em uma sociedade em rede que gera cultura e conhecimento. Todo esse processo nos impacta de uma maneira que, atualmente, lidamos dialeticamente com questões de autonomia, democracia, liberdade e controle. Ademais, essas tecnologias trouxeram novas formas de acesso ao conhecimento, compartilhamento de informações, interatividade e colaboração. Com as comunidades virtuais estruturadas em redes, novas formas de organização social foram configuradas e ordenadas pela sociedade. Entretanto, esse paradigma de acesso à internet aumenta a desigualdade e a exclusão sociais já existentes (Castells, 2003).

Para Sorj e Guedes (2005), mesmo que boa parte da literatura compartilhe da idéia do potencial das TICs, a prática ocorre de modo inverso: como o modelo de sociedade informacional demanda apropriação e uso das novas tecnologias digitais, a não adequação a essa sociedade resulta em desigualdade e até exclusão social. O sistema acaba expulsando os indivíduos que não participam dessa lógica digital, o que dificulta ainda mais o acesso deles às novas tecnologias. Dessa maneira, a exclusão digital e a exclusão social tornaram-se consequência uma da outra.

$\mathrm{Na}$ área da saúde, há muitos ambientes virtuais construídos por diversas instituições, empresas e pessoas. No entanto, como as informações de saúde podem ser publicadas e compartilhadas sem qualquer tipo de avaliação, as informações incorretas, incompreensíveis ou mesmo desatualizadas podem prejudicar a saúde dos cidadãos. Em contrapartida, as informações de saúde de qualidade, disseminadas na internet, podem influenciar positivamente a vida dos cidadãos e, consequentemente, podem contribuir para reduzir os custos dos sistemas de saúde. Afinal, há numerosos sites com informações de saúde que se referem a nutrição, bem-estar, atividades físicas, medicamentos e doenças, dentre tantas outras pautas (Neto; Flynn, 2019, p. 16). Portanto, é necessária a realização de iniciativas de inclusão digital, divulgação científica, educação que minimizem os efeitos danosos da desinformação no mundo cibernético. Neste contexto, desde 2012, o Laboratório Internet, Saúde e Sociedade (LaISS), integrante do Centro de Saúde Escola Germano Sinval Faria (CSEGSF), da Escola Nacional de Saúde Pública (ENSP) da Fundação Oswaldo Cruz (FIOCRUZ), iniciou as oficinas de alfabetização digital para a população de Manguinhos, com o objetivo de desenvolver habilidades e competências necessárias para ouso de computadores e celulares. Em julho de 2019, foram iniciadas as oficinas de literacia digital em saúde de maneira presencial; entretanto, em 13 de março de 2020, devido à pandemia da Covid-19 e de acordo com o Plano de Contingência da Fiocruz, as oficinas presenciais foram interrompidas. Em abril de 2020, as atividades foram reiniciadas,-de modo on-line, em um grupo no aplicativo WhatsApp ${ }^{{ }^{1}}$, que já era usado para a comunicação dos alunos com a equipe pedagógica.

De acordo com os Objetivos de Desenvolvimento Sustentável (ODS) para 2030, estabelecidos pela Organização das Nações Unidas (ONU), a disseminação da informação e das tecnologias da comunicação e a interconectividade global têm um grande potencial para acelerar o progresso humano, eliminar o "fosso" digital e desenvolver sociedades do conhecimento (Onu, 2015). Afinal, por meio das novas TICs, em especial a internet, as informações são disponibilizadas em alta velocidade e acessadas por diversos dispositivos e lugares (Levy, 2010).

Segundo uma pesquisa realizada pelo Instituto Brasileiro de Geografia e Estatística (IBGE), em 2016, 64,7\% da população brasileira estava conectada à internet. Ainda assim, 63,3 milhões de pessoas (37,8\%) ainda estavam off-line por não saberem utilizar as ferramentas digitais. Nesse sentido, embora seja perceptível o gradual crescimento do acesso à internet em

${ }^{1}$ WhatsApp - É um aplicativo multiplataforma de mensagens instantâneas, áudios e chamadas de voz para smartphones. 
diferentes níveis socioeconômicos da sociedade brasileira, delineiam-se disparidades diretamente relacionadas ao poderio econômico e à utilização do computador com acesso à internet (Ibge, 2016).

Dentre as inúmeras tecnologias que permeiam o cenário contemporâneo, a internet serve como via de mão dupla na sua função de comunicar e informar. Destaca-se ainda como um formato que emerge da relação entre sociedade, cultura e tecnologias digitais, rompendo com a dinâmica informacional baseada na relação "Um para Todos" e potencializando as trocas de "Todos para Todos", em que cada indivíduo é simultaneamente um emissor e receptor de informações (Couto, 2012).

Diante disso, torna-se evidente a importância da inclusão digital para moradores de comunidades vulneráveis, como forma de diminuir as desigualdades associadas à exclusão digital. Em uma sociedade cada vez mais dominada pela tecnologia digital, a falta de conhecimento, domínio e manuseio dessas ferramentas aumentam as desigualdades sociais. Por isso, difundir o uso das tecnologias e desenvolver mecanismos de leitura e recepção crítica das informações adquiridas por meio das TICs é promover a cidadania e a participação social.

A literacia, letramento ou alfabetização em saúde consiste no conhecimento básico de saúde e nas competências presentes para atender as demandas de saúde. As quatro competências são: (1) Acessar, que se refere à habilidade de pesquisar e encontrar as informações de saúde; (2) Entender, que diz respeito à capacidade de compreender a informação obtida; (3) Avaliar, que engloba a capacidade de interpretar, filtrar e julgar a informação obtida; e (4) Aplicar, que se refere à habilidade de comunicar a informação recebida. Essas competências, quando adquiridas, promovem o domínio do cuidado da saúde, da prevenção de doenças e da promoção da saúde (Sørensen et al., 2012).

A promoção da saúde representa um importante avanço no conceito de saúde: a conferência da ONU realizada em 1986, em Ottawa, no Canadá, preconizou que a saúde não é somente a ausência de doenças, mas também é o bem-estar físico, mental e social do indivíduo. Portanto, promover a saúde é melhorar não só a saúde, mas a qualidade de vida da população (Buss, 2000). O congresso de promoção da saúde da ONU, realizado em 2009, destaca a importância da literacia em saúde para o desenvolvimento sustentável e para a promoção da saúde. Embora não haja uma agenda específica sobre alfabetização em saúde nos Objetivos de Desenvolvimento Sustentável (ODS), os esforços para aumentar a alfabetização em saúde são cruciais para o desenvolvimento sustentável e o atendimento da Agenda 2030, em especial, em países de baixa renda (Onu, 2015).

Em um mundo cada vez mais conectado, a literacia em saúde também se associa ao acesso às informações de saúde por meio de dispositivos eletrônicos. Essa associação se traduz no conceito de E-Health Literacy, ou alfabetização digital em saúde, definido pelas habilidades de Procurar, Encontrar, Entender e Avaliar os conhecimentos adquiridos para abordar ou resolver um problema de saúde. Para o desenvolvimento dessas habilidades, são necessários conhecimentos que formam o "Modelo de Lily", composto de seis conhecimentos: (1) Tradicional, que se refere à habilidade de ler, falar e entender a escrita; (2) Saúde, que é a habilidade de ler e entender informações de saúde; (3) Informação, que é a aptidão de saber encontrar a informação, organizar, filtrar e catalogar; (4) Ciência, que é a habilidade de entender o conhecimento científico e a compreensão das informações de saúde on-line baseadas na ciência; (5) Mídia, que é a competência de conhecer o conteúdo de uma mídia e as relações com o público; e (6) Informática, que é a capacidade de usar computadores e meios digitais (Norman; Skinner, 2006).

$\mathrm{Na}$ Inglaterra, está em curso um projeto para a classe de trabalhadores que tem por objetivo a inclusão digital e seus componentes para os domínios da literacia e a promoção da saúde (Health Education England, 2019). No Canadá, o conhecimento de informações básicas de saúde é considerado muito importante, visto que os sistemas de saúde estão cada vez mais complexos e demandam que os indivíduos assumam um alto grau de autonomia (Rootman et al., 2008). Em Portugal, foram realizadas diversas pesquisas sobre esse assunto e, em uma delas, observaram que a população de oito estados apresentava baixa literacia em saúde (Costa A.; Saboga-nunes; Costa L., 2016). 
Assim, para promover a literacia em saúde, o LaISS iniciou oficinas de alfabetização digital em Saúde, em julho de 2019, com um encontro presencial por semana, para uma turma de aproximadamente 15 alunos. No começo, o conteúdo abordou a procura de informações de saúde na internet e como identificar informações falsas em saúde, as fake news (em português, notícias falsas). Posteriormente, diversos temas em saúde foram abordados com diferentes profissionais de saúde, possibilitando uma experiência enriquecedora para os alunos. Tendo como a principal proposta da pesquisa a diminuição da exclusão digital e a desinformação em saúde.

\section{Metodologia}

A metodologia da pesquisa foi qualitativa pois buscou observar e interpretar fenômenos da realidade, para a comparação entre a observação e a formulação de conceitos (Pereira et al. 2018; Estrela2018; Ludke et al., 2013; Yin2015; Severino2018).

Os conteúdos das oficinas foram elaborados a partir da realidade e das necessidades dos alunos, numa prática de problematização das questões vividas pelos educandos. Além disso, a equipe procurou construir um relacionamento horizontal entre educando e educador, a fim de diminuir o papel de autoridade do educador, uma vez que essa prática inviabiliza a criticidade e a conscientização do educando (Freire, 2002).

Os participantes das oficinas fazem parte da população de Manguinhos, um bairro na zona norte da cidade do Rio de Janeiro, no entorno da Fiocruz, que possui um dos menores Índices de Desenvolvimento Humano da cidade (IPP, 2019). Segundo dados da pesquisa "Condições de vida e saúde e uso de serviços de saúde no território Teias-Escola Manguinhos", mais da metade da população de Manguinhos não cursou o Ensino Fundamental completo. Em relação à moradia, a maioria mora em casas de alvenaria com luz elétrica, onde 40\% têm acesso à internet e 90\% possuem celular (Informe Ensp, 2012).

O espaço físico do laboratório foi um fator limitante nas aulas presenciais, porque comporta apenas onze computadores, sendo dez para os participantes e um para o mediador. A equipe era composta por uma coordenação pedagógica e dois estagiários de nível superior e/ou médio. Em Março de 2020, com a pandemia da Covid-19, em decorrência das medidas de distanciamento social, as oficinas presenciais foram transformadas em oficinas on-line síncrona por meio do grupo de WhatsApp já existente com 60 alunos, 6 professores e 3 pesquisadores. Há 02 modalidades de oficinas on-line: alfabetização digital e literacia em saúde. Cada oficina on-line síncrona consiste na exibição de uma videoaula seguida de um bate-papo no formato perguntas e respostas com os professores.

As videoaulas são gravadas previamente e hospedada no canal Laboratório Internet, Saúde e Sociedade (LaISS) na plataforma YouTube ${ }^{\circledR 2}$. Cada videoaula possui uma duração média de 20 minutos. As de alfabetização digital são produzidas e apresentadas pela equipe pedagógica do LAISS e as de literacia em saúde são produzidas e apresentadas pelos professores convidados.

No dia da oficina, em um horário padrão predeterminado, o professor é convidado a dialogar no grupo de WhatsApp ${ }^{\circledR}$ com os alunos sobre o tema durante 90 minutos, em média. As oficinas ocorrem duas vezes por semana com a média de 15 alunos, sendo duas oficinas de alfabetização digital e uma oficina de literacia em saúde. Nesta ocasião os alunos são convidados a dar sua opinião sobre as aulas.

\section{Resultados}

No LaISS, as experiências com alfabetização digital anteriores ao primeiro semestre de 2019 envolviam o ensino e o uso do pacote Office ${ }^{\circledR}$ da Microsoft, em especial para preparar os jovens e reinserir os adultos no mercado de trabalho. Devido ao crescente uso do celular como computador portátil, também foram realizadas oficinas de aprendizagem do manuseio de celulares. Para a participação das oficinas não havia pré-requisito que pudesse excluir participantes, sendo necessária apenas a 
vontade de aprender ferramentas digitais e de desenvolver habilidades para acesso crítico e criativo das informações disponibilizadas na internet; sem restrições quanto ao nível de escolaridade, a participação abrangeu tanto jovens quanto idosos. Foi definido, que o tempo de permanência nesse processo de ensino-aprendizagem seria indeterminado; e assim continua, porque esse processo é de educação permanente e, a cada dia, requer atualizações e aquisição de novos conhecimentos.

Como resultados das oficinas de literacia digital em saúde, os alunos puderam identificar informações falsas e verdadeiras na internet, pesquisar doenças e tratamentos, entender melhor os seus problemas de saúde, aprender a necessidade de fazer exercícios físicos, participar das campanhas de vacinação, evitar o tabagismo e o alcoolismo, e obter informações sobre alimentação saudável. Além disso, os alunos puderam tirar dúvidas com os professores das videoaulas por meio da oficina on-line síncrona no Whatsapp ${ }^{\circledR}$.

O perfil dos usuários foi avaliado em dezembro de 2019, foi observado que $70 \%$ dos alunos têm mais de 60 anos e $19 \%$ têm entre 40 e 50 anos; 76\% são mulheres e 60\% são aposentados. Uma nova avaliação do perfil foi realizada em dezembro de 2020, os dados foram similares: a maioria dos alunos é composta por mulheres (70\%), aposentados (64\%) e com idade superior a 60 anos (73\%). Os usuários foram convidados a opinar sobre as oficinas, tendo sido verificado que $91 \%$ dos alunos consideraram que as oficinas de literacia em saúde auxiliaram no autocuidado e $82 \%$ que as aulas sobre a doença Covid-19 auxiliaram a prevenção da doença. Todos consideraram como vantagem das oficinas on-line o fato de contribuírem com o isolamento social previsto como medida de prevenção ao Covid-19. Outras vantagens comentadas pelos alunos foram a possibilidade de assistir às aulas no YouTube ${ }^{\circledR}$, posteriormente, e escutar todos os comentários no grupo de WhatsApp ${ }^{\circledR}$, mesmo depois da atividade síncrona com o professor.

Os alunos relatarem livremente suas opiniões sobre as oficinas. Seguem alguns relatos dos alunos:

"As minhas aulas preferidas são as de vídeos interativos, que incentivam as pessoas da comunidade de Manguinhos a conhecerem o LaISS e aprender muitas coisas no computador” (12/2019 - Aluno A).

"O curso é muito bom! Quando eu cheguei aqui não sabia nada e hoje eu já aprendi um pouco e quero aprender mais” (12/2019 - Aluno B).

"Só agradecimentos, aprendi muito e estou feliz com a atenção que vocês deram para a gente no momento da pandemia” (12/2020 - Aluno C).

“As aulas são muito importantes para mim, me ajudam na pandemia a não me sentir sozinha” (12/2020 - Aluno D).

Antes da pandemia do Covid-19, foram realizadas rodas de conversa presenciais, com o objetivo de promover uma maior aproximação dos alunos com a equipe de educadores. Nesses encontros, foram solicitadas as opiniões dos alunos sobre as oficinas e suas experiências na utilização das tecnologias e no conhecimento da literacia em saúde. Assim, foi possível identificar que o conhecimento das TICs possibilitou uma melhoria na qualidade de vida dos participantes, devido ao acesso a informações que estimularam mudanças e novas perspectivas de vida. Alguns alunos voltaram a estudar no curso da EJA (Educação de Jovens e Adultos) e ainda criaram páginas no Facebook $\circledR^{2}$ para compartilharem seus conhecimentos e para promover seus negócios. Alguns jovens conseguiram estágios e empregos, e outro ingressou em uma universidade federal para a área de tecnologia da informação.

No período da pandemia da Covid-19, foram produzidas 20 vídeoaulas de alfabetização digital e mais 20 sobre literacia em saúde, com os conteúdos, em sua maioria, escolhidos pelos alunos. Os participantes aderiram imediatamente à

${ }^{2}$.Facebook - É uma mídia social e rede social virtual 
nova abordagem de uso de recursos digitais no processo de ensino-aprendizagem, convidando e agregando novos moradores da comunidade. Nas aulas de literacia em saúde, no início da pandemia, foram transmitidas informações sobre Covid-19, abordando aspectos de prevenção e sintomas. Posteriormente, foram iniciadas parcerias com profissionais de saúde de nutrição, medicina, assistência social, educação física e com terapeutas de práticas integrativas e complementares em saúde, além de aulas de fotografia digital, para apresentação de temas específicos de interesse dos participantes. Ao final do ano de 2020, foram registradas um total de aproximadamente 88 oficinas de inclusão digital e 44 de literacia em saúde.

Após a apresentação das videoaulas gravadas no grupo de WhatsApp ${ }^{\circledR}$, os alunos interagiam com os professores enviando áudios no WhatsApp ${ }^{\circledR}$ com perguntas e tinham suas dúvidas esclarecidas pelo professor. Depois das oficinas on-line por meio do Whatsapp ${ }^{\circledR}$, foi oferecido pela equipe pedagógica a possibilidade do encontro ser por vídeo através do aplicativo GoogleMeet $\AA^{3}$. A grande maioria dos alunos concordou e foi possível a realização de oficinas utilizando o GoogleMeet ${ }^{\circledR}$. Nesse processo de transição, alguns alunos tiveram dificuldade com incorporação do recurso por vídeo que foram superadas com o passar do tempo. A intenção de incluir o recurso visual pela equipe pedagógica do LaISS vai de encontro com a aquisição de novas habilidades com as TICs.

$\mathrm{Na}$ avaliação realizada com os professores, realizado em Dezembro 2020, foi verificado que $89 \%$ dos profissionais de saúde consideraram que as oficinas do LaISS complementaram as informações do atendimento individual, $78 \%$ afirmaram que as oficinas auxiliaram na prevenção da doença, 56\% disseram que as oficinas podem contribuir para evitar filas no Centro de Saúde e $89 \%$ consideraram ótima a participação dos alunos e o aproveitamento do conteúdo. Os professores foram unânimes em considerar que foi boa a iniciativa de realizar as oficinas de modo on-line.

O perfil do público que participou dessa experiência educacional com inovações no processo de ensino-aprendizagem é permeado por disparidades significativas. Há usuários que já possuíam experiência em informática, enquanto outros nunca tiveram a oportunidade de manusear um computador. Há aqueles que, apesar de frequentar as oficinas nos semestres anteriores, ainda não conseguiam realizar determinados procedimentos básicos, necessitando de orientação ou constante supervisão dos mediadores desse processo.

Cabe ressaltar que o processo de aprendizado, além de não se configurar de maneira retilínea, uniforme e instantânea, é atravessado por obstáculos como o analfabetismo funcional e as dificuldades cognitivas e motoras. No entanto, o engajamento e o esforço dos alunos foram fundamentais para a superação de tais obstáculos, assim como para o desenvolvimento de suas habilidades e autonomia em informática e acesso às mídias digitais. Desde 2012, cerca 400 alunos participaram das oficinas.

\section{Considerações Finais}

A utilização de computadores, tablets e smartphones estão presentes nos diversificados setores da sociedade brasileira. A popularização do uso de celulares e a ampliação do acesso à internet sem fio possibilitaram que um número cada vez maior de pessoas consiga acessar, produzir e compartilhar informações anteriormente restritas a determinados grupos sociais. Entretanto, os benefícios das TICs não ocorrem de maneira igualitária na sociedade, sendo necessários projetos educacionais de inclusão digital, no campo da educação não formal, para a população menos favorecida. Além disso, a propriedade de um dispositivo com acesso a internet é um recurso premente para a inclusão digital especialmente no cenário da pandemia do Covid-19, em decorrência da aceleração da virtualização dos serviços públicos que promovem a cidadania. Assim a atuação do Estado em prover o acesso a internet é urgente.

\footnotetext{
${ }^{3}$.GoogleMeet - É uma plataforma de videoconferência do Google.
} 
A alfabetização digital trouxe benefícios de inclusão digital e social para os alunos dentro da perspectiva da promoção da saúde. No início da pandemia da Covid-19, as oficinas on-line com conteúdos referentes a sintomas da doença (febre, tosse, dificuldade de respirar, dor no peito, entre outras) e medidas de prevenção (uso de máscara, higienização das mãos, isolamento social, entre outras) reforçaram a necessidade do autocuidado. Essa modalidade de aprendizado trouxe regularidade na frequência, participação ativa, compartilhamento dos conteúdos, adesão de novos moradores e ampliação da rede social dos moradores. A utilização de oficinas on-line possibilitou a continuidade das oficinas que antes eram realizadas de forma presencial. Foi observada uma maior conscientização nas medidas de prevenção da doença, o sentimento de pertencimento e a mitigação do sofrimento gerado pelas medidas de distanciamento social.

As oficinas educativas em saúde e inclusão digital devem ser incentivadas para fomentar e desenvolver mecanismos de leitura e reflexão crítica das informações adquiridas por meio das TICs, a fim de diminuir a exclusão digital, promover a saúde o autocuidado e a cidadania. Por fim, cabe destacar a necessidade de ampliar programas governamentais de inclusão digital e literacia em saúde que atendam às necessidades da população, contribuindo para melhorar a saúde e o bem-estar da população de baixa renda. Como sugestão para trabalhos futuros, recomendamos a avaliação das ações educativas para a prevenção e o resultado alcançado para evitar a contaminação da Covid-19.

\section{Agradecimentos}

As equipes do Centro de Saúde Escola Germano Sinval da Silva Filho e do Laboratório de Internet Saúde e Sociedade e do seu coordenador Prof. André Pereira Neto pela possibilidade de realização deste trabalho.

\section{Referências}

Buss, P. M. (2000). Promoção da saúde e qualidade de vida.Ciência\& saúde coletiva, v. 5, p. 163-177.

Castells, M. A (2016). Galáxia Internet: reflexões sobre a Internet, negócios e a sociedade. [s.1.] Zahar.

Costa, A.; Saboga-Nunes, L. \& Costa, L. (2003). Avaliação do nível de literacia para a saúde numa amostra portuguesa.

Couto, M. E. S. (2012). Alfabetização e letramento digital. Estudos IAT, v. 2, n. 1.

Ensp. Pesquisa aponta mudanças na população de Manguinhos. http://www.ensp.fiocruz.br/portal-ensp/informe/site/materia/detalhe/31100

Estrela, C. (2018). Metodologia Científica: Ciência, Ensino, Pesquisa. Editora Artes Médicas.

Freire, P. (2002). Pedagogia da autonomia: saberes necessários à prática educativa. São Paulo: Paz e Terra.

Health EducationEngland, Digital Lieracy. https://www.hee.nhs.uk/our-work/digital-literacy

Ibge. Pnad Contínua TIC 2016: 94,2\% das pessoas que utilizaram a Internet o fizeram para trocar mensagens. https://agenciadenoticias.ibge.gov.br/agenciasala-de-imprensa/2013-agencia-de-noticias/releases/20073-pnad-continua-tic-2016-94-2-das-pessoas-que-utilizaram-a-internet-o-fizeram-para-trocarmensagens

Ipp. Índice de Desenvolvimento Humano (IDH) Municipal, por ordem de IDH, segundo os Bairros ou grupo de Bairros, no Município do Rio de Janeiro em 1991/2000. http://www.data.rio/datasets/58186e41a2ad410f9099af99e46366fd

Levy, P. (2010). Cibercultura. São Paulo (SP): Ed. 34.

Ludke, M. \& Andre, M. E . D. A. (2013). Pesquisas em educação: uma abordagem qualitativa. São Paulo: E.P.U.

Neto, A. P.; Flynn, M. B. (2019). The Internet and Health in Brazil: Trends and Challenges. In: The Internet and Health in Brazil. [s.1.] Springer, p. 1-11.

Norman, C. D.; Skinner, H. A. (2006). e-Health Literacy: Essential Skills for Consumer Health in a Networked World.Journal of Medical Internet Research, v. 8 , n. 2 ,

ONU. United Nations Sustainable Development, 2015. https://www.un.org/sustainabledevelopment

Pereira A. S. et al. (2018). Metodologia da pesquisa científica. [free e-book]. Santa Maria/RS. Ed. UAB/NTE/UFSM. 
Research, Society and Development, v. 11, n. 3, e11011326415, 2022

(CC BY 4.0) | ISSN 2525-3409 | DOI: http://dx.doi.org/10.33448/rsd-v11i3.26415

Rootman, I. et al. (2008). A vision for a health literate Canada: report of the Expert Panel on Health Literacy. Ottawa, Ont.: Canadian Public Health Association,.

Severino, A. J. (2018). Metodologia do trabalho científico. SãoPaulo: Cortez.

Sørensen, K. ., Van den Broucke, S., Fullam, J., Doyle, G., Pelikan, J., Slonska, Z., \& Brand, H. (2012). Health literacy and public health: a systematic review and integration of definitions and models. BMC public health, v. 12, n. 1, p. 80

Sorj, B.; Guedes, L. E. (2005). Exclusão digital: problemas conceituais, evidências empíricas e políticas públicas.Novos estudos CEBRAP, n. 72, p. 101-117. Yin, R.K. (2015). O estudo de caso. Porto Alegre: Bookman. 